\title{
COMPUTER SIMULATION OF MOORED SHIP MOTION INDUCED BY HARBOR RESONANCE IN POHANG NEW HARBOR
}

\begin{abstract}
Moonsu Kwak ${ }^{1}$, Yongho Moon ${ }^{2}$ and Chongkun Pyun ${ }^{3}$
This paper proposes a computational method for estimating moored ship motion taking into consideration harbor resonance, and provides a way to estimate the effect that harbor resonance has on moored ship motion. The computation of harbor resonance used the CGWAVE model, and the computation of moored ship motion used the three-dimensional Green's function method. This method was verified with field motion measurement data from actual moored ships and wave field data and down time record data from Pohang New Harbor. The resonance periods obtained from wave field data in Pohang New Harbor were 80, 33, 23, and 8 min, which were the long waves, and 42, 54 , and $60 \mathrm{~s}$, which were the infra-gravity waves inside the harbor slip. The simulation results for harbor resonance were compared to the actual wave field data. This study investigated whether harbor resonance has an effect on moored ship motion using simulated results of ship motion both with and without harbor resonance included. In the case of harbor resonance included, moored ship motion increased by 10-30\% when compared with the results without harbor resonance included. We found that harbor resonance has a greater effect on the surge and heave motion of a large-sized ship and on the roll and the yaw motion of a small-sized ship.
\end{abstract}

Keywords: moored ship motion, harbor resonance, Pohang New Harbor, infra-gravity waves, CGWAVE model, Green function method

\section{INTRODUCTION}

The cause of down time when loading and unloading activities of the ship comes from moored ship motion that is induced by long waves, short waves, harbor resonance, wind, and mooring systems. When the natural period of a ship matches the resonance period of a harbor, the moored ship motion increases. If we can estimate moored ship motion considering harbor resonance, it is possible to reduce downtime of loading and unloading, reduce damage from mooring systems, and increase the effective harbor working day.

In a study on moored ship motion, Ueda and Shiraishi (1998) proposed an estimating method for the harbor working day considering moored ship motion. This method can estimate the harbor working day in berth by obtaining the nonexceedance probability of deep water wave height during possible loading and unloading times. Kubo et al. (1993) studied a simple method for estimating a harbor working day using a numerical model to compute moored ship motion. In particular, they studied the effects that a fender system has on moored ship motion. Ueda et al. (1994) obtained the harbor working day by simulating moored ship motion and the allowable wave height for loading and unloading. Recently, Sakakibara et al. (2001) measured moored ship motion using several cameras, and verified the simulation results of moored ship motion in a time domain analysis. Kwak et al. (2006) proposed an estimating method for harbor working day by simulating moored ship motion. They indicated the problem that down time occurs in harbors designed with standard wave heights.

In this study, we estimate the effect that harbor resonance has on moored ship motion in order to reduce the down time for loading and unloading, and to reduce the damage to moored ships when the natural frequency of the ship matches the resonance frequency of the harbor. A proposed computation method for moored ship motion induced by harbor resonance is provided in this study. The computation of harbor resonance used the CGWAVE model, and the computation of moored ship motion used the three-dimensional Green's function method. This method was verified with field measurements from actual moored ship motion and with wave field data and down time record data

\footnotetext{
${ }^{1}$ Ph.D., Professor of Civil Engineering, Myongji College, 134 Gajwa-ro, Seodaemun, Seoul 120-776, Korea (moonsu@mjc.ac.kr)

${ }^{2}$ Graduate student, Civil and Environmental Engineering, Myongji University, Yongin, Kyonggi 449-728, Korea

${ }^{3}$ Ph.D., Professor of Civil and Environmental Engineering, Myongji University, Yongin, Kyonggi 449-728, Korea (ckpyun@mju.ac.kr)
} 
from Pohang New Harbor.

WAVE MODEL FOR SIMULATING HARBOR RESONANCE

\section{Governing equations}

The two-dimensional elliptic mild-slope wave equation is an accepted method for modeling surface gravity waves in coastal areas. This equation may be written as follows (Demirbilek and Panchang, 1998):

$$
\nabla \cdot\left(\mathrm{CC}_{\mathrm{g}} \nabla \hat{\eta}\right)+\frac{\mathrm{C}_{\mathrm{g}}}{\mathrm{C}} \sigma^{2} \hat{\eta}=0
$$

where

$$
\begin{aligned}
\hat{\eta}(x, y)= & \text { complex surface elevation function, from which the wave height can be estimated } \\
\sigma & \text { wave angular frequency } \\
\mathrm{C}(x, y)= & \text { phase velocity }=\sigma / \mathrm{k} \\
\mathrm{C}_{\mathrm{g}}(x, y)= & \text { group velocity }=\partial \sigma / \partial \mathrm{k}=\mathrm{nC} \text { with } \\
& n=\frac{1}{2}\left(1+\frac{2 k d}{\sinh 2 k d}\right) \\
k(x, y)= & \text { wave number }(=2 \pi / \mathrm{L}), \text { related to the local depth } \mathrm{d}(\mathrm{x}, \mathrm{y}) \text { through the linear dispersion } \\
& \text { relation: } \\
& \sigma^{2}=g k \tanh (k d)
\end{aligned}
$$

Equation 1 simulates wave refraction, diffraction, and reflection (i.e., the general wave scattering problem) in coastal domains of arbitrary shape. However, various other mechanisms also influence the behavior of waves in a coastal area. The mild-slope wave equation can be modified as follows to include the effects of frictional dissipation (Dalrymple et al., 1984) and wave breaking (Dally et al., 1985):

$$
\nabla \cdot\left(\mathrm{CC}_{\mathrm{g}} \nabla \hat{\eta}\right)+\left(\frac{\mathrm{C}_{\mathrm{g}}}{\mathrm{C}} \sigma^{2}+i \sigma w+i \mathrm{C}_{\mathrm{g}} \sigma \gamma\right) \hat{\eta}=0
$$

Where $w$ is a friction factor and $\gamma$ is a wave breaking parameter. Following Dalrymple et al. (1984), we used the following form of the damping factor in CGWAVE:

$$
\omega=\left(\frac{2 \mathrm{n} \sigma}{k}\right)\left[\frac{2 f_{r}}{3 \pi} \frac{a k^{2}}{(2 k d+\sinh 2 k d) \sinh k d}\right]
$$

where a $(=\mathrm{H} / 2)$ is the wave amplitude and $f_{r}$ is a friction coefficient to be provided by the user. The coefficient depends on the Reynolds number and the bottom roughness and may be obtained from Madsen(1976) and Dalrymple et al.(1984). Typically, values for are in the same range as for Manning's dissipation coefficient. Specifying as a function of allows the modeler to assign larger values for elements near harbor entrances to simulate entrance loss. For the wave breaking parameter, we use the following formulation (Dally et al., 1985; Demirbilek, 1994; Demirbilek et al., 1996):

$$
\gamma=\frac{\chi}{d}\left(1-\frac{\Gamma^{2} d^{2}}{4 a^{2}}\right)
$$

where $\chi$ is a constant (a value of 0.15 is used in CGWAVE following Dally et al., (1985)) and is an empirical constant (a value of 0.4 is used in CGWAVE). 
In addition to the above mechanisms, nonlinear waves may be simulated with the mild-slope wave equation. This is accomplished by incorporating amplitude-dependent wave dispersion, which has been shown to be important in certain situations (Kirby and Dalrymple, 1986). The nonlinear dispersion relation used in place of Eq. (3) is

Where

$$
\left.\begin{array}{c}
\sigma^{2}=g k\left[1+(k a)^{2} F_{1} \tanh ^{5} k d\right] \tanh \left(k d+k a F_{2}\right) \\
F_{1}=\frac{\cosh (4 k d)-2 \tanh ^{2}(k d)}{8 \sinh ^{4}(k d)} \\
F_{2}=\left(\frac{k d}{\sinh (k d)}\right)^{4}
\end{array}\right\}
$$

\section{Verification of wave model}

\section{- Numerical simulation conditions}

In this study, the CGWAVE model is applied to Pohang New Harbor in order to simulate harbor resonance and to verify the model against field measurement wave data (Pohang Regional Maritime Affairs and Port office, 2010). The simulation domain is $13.5 \mathrm{~km}$ in the offshore direction and $9.5 \mathrm{~km}$ in the longshore direction. A finite element model (FEM) mesh was set up with 5-20 m inside the harbor and 50-200 m outside the harbor, which took into consideration the simulation time and wave length with an arbitrary water depth. The FEM model was made up of 67,052 elements and 35,622 nodes. The incident wave periods were set to range from 30 second to 100 minute, and the incident wave angle was set to a north-east (NE) direction. The simulation domain and the FEM mesh model are shown Figure 1. In this study, the reference points were set at W03, which is located near pier 8 in Pohang New Harbor, and W10, which is located near pier 7 (Figure 2). Piers 7 and 8 were berthing 5,000-30,000 deadweight tonnage (DWT)--sized ships.

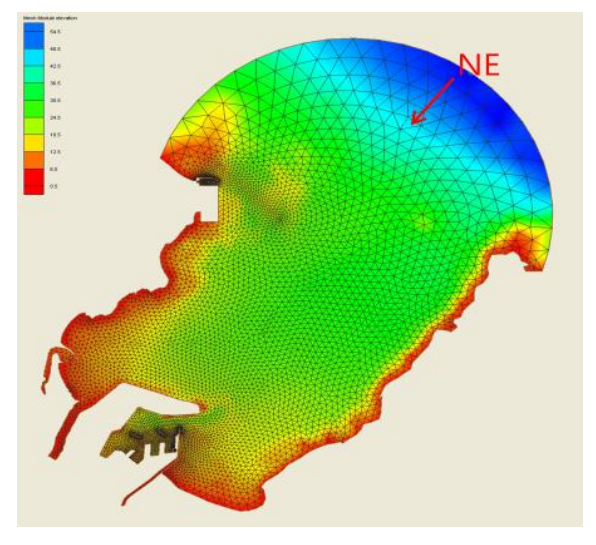

Figure 1. Layout of simulation domain with FEM mesh and wave direction.

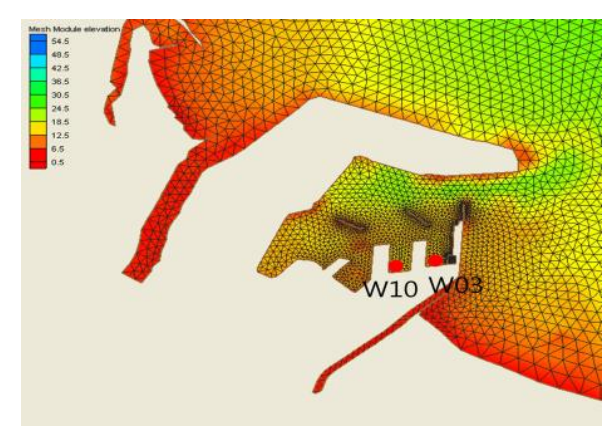

Figure 2. Close up domain of the Pohang New Harbor with wave measurement stations

\section{- Results of the numerical simulation}

Figure 3 shows the field data (spectral density with wave periods) at station W03. The resonant periods that have effect on moored ship motion are shown at 80,33,23, and 8 minute in long waves, and at $0.7,0.9$, and 1.0 minute in infragravity waves. It was found that the numerical simulation results (shown in Figure 4) accurately captured the peak resonant periods from the field data. Figure 5 shows 
the field data at station W10. This station has resonant periods that are very similar to station W03. Figure 6 shows that the numerical simulation results for station W10 corresponded well to the field data.

In addition, Figure 7 compares the relative amplitude in the simulation results with the field data for stations W02 and W03. The error ranges for both results are shown at $\pm 5 \sim 10 \%$.

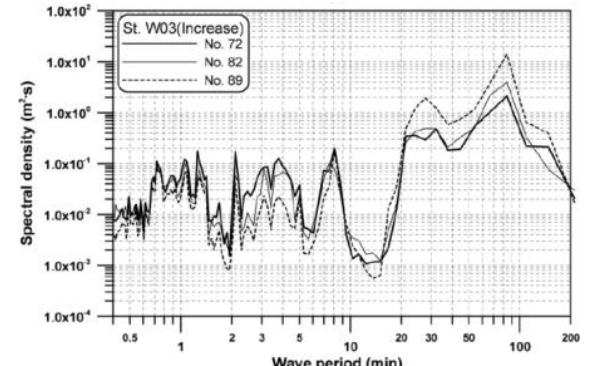

Figure 3. Result of field measurement at W03.

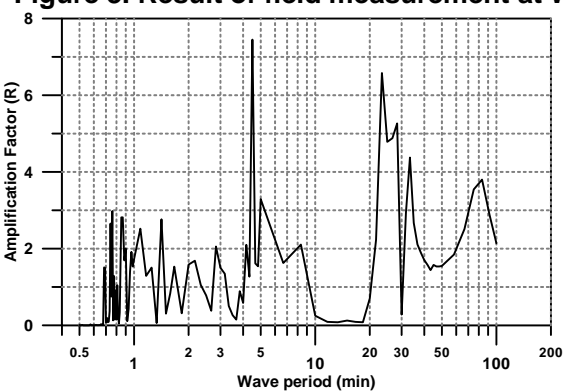

Figure 5. Result of computer simulation at W03.

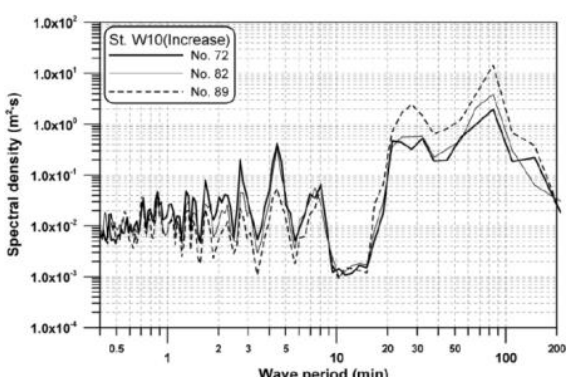

Figure 4. Result of field measurement at W10.

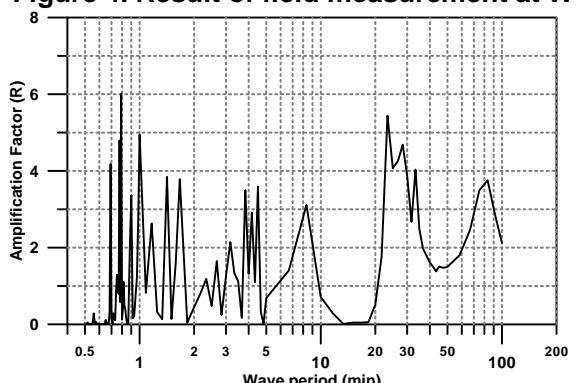

Figure 6. Result of computer simulation at W10.

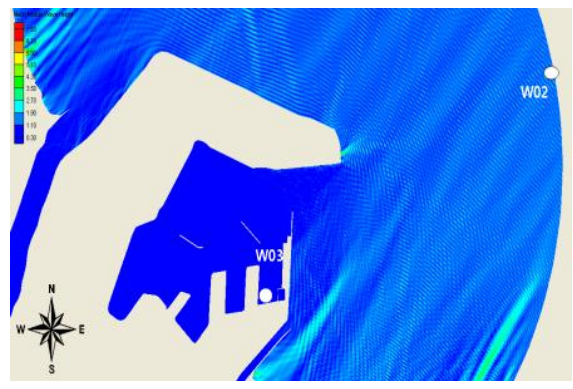

Figure 7. Location map of the reference points for comparison of wave amplitude.

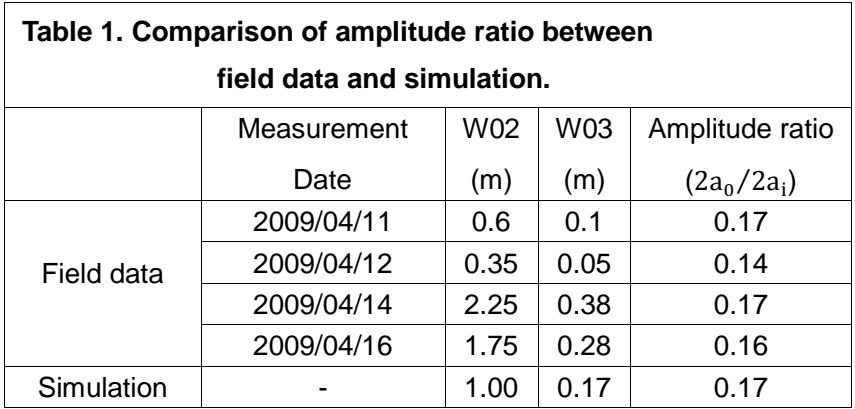

\section{SHIP MODEL FOR SIMULATING MOORED SHIP MOTION}

\section{Governing equations}

The forces that affect a moored ship in fluid are fluid dynamic and static forces induced by ship motion, incident waves, and mooring equipment. Wave force, which is one of the fluid dynamic forces, 
acts on a moored ship when the waves propagate around the ship. It is impossible to solve for these forces precisely. Therefore, instead of a physical model, we chose a numerical model with various assumptions. The numerical model used in this study was developed by linearizing the fluid dynamic and wave forces, which are variables of ship motion. We assumed that moored ship motion was small, and introduced a potential velocity for the numerical model.

It is difficult to solve for moored ship motion directly due to the irregular wave field that occurs in a harbor. Therefore, we expressed the irregular wave field as a superposition of many regular waves. Furthermore, the numerical model was used to solve an irregular wave field by spectrum analysis, which was obtained from moored ship motion on a regular wave field. The Bretschneider spectrum, with parameters expressed in significant wave height and period, was used in this study.

Mooring equipment includes mooring lines and fenders that cause nonlinear moored ship motion. However, we assumed a mooring force of linear motion in order to analyze ship motion in the frequency domain. The linear momentum equation for ship motion on a regular wave field is shown below (Kwak et al., 2006).

$$
\left[-\omega^{2}\left(M_{j k}+A_{j k}\right)+i \omega B_{j k}+R_{j k}\right] a_{j k}=F_{j}
$$

Where,

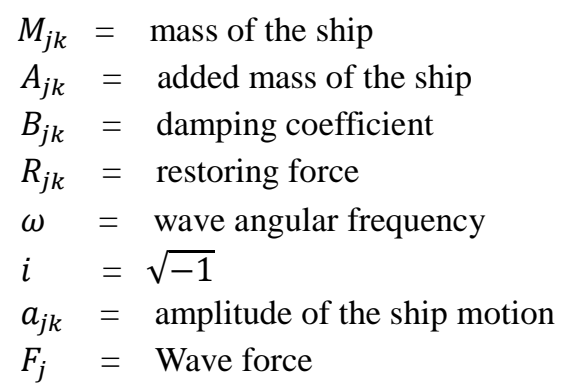

\section{Computational method of ship oscillation quantity}

\section{- Computational method of ship oscillation quantity from short waves}

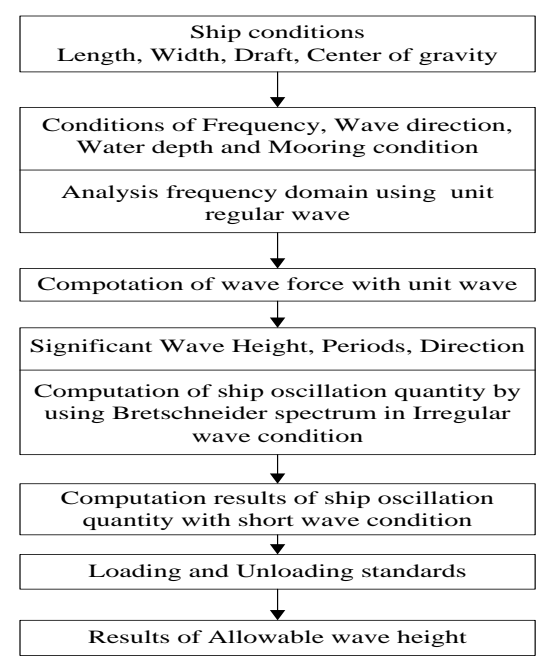

Figure 8. Flow chart of the computational procedure for ship oscillation quantity by short wave.

The flow chart for computing ship oscillation from short waves is shown in Figure 8. First of all, the model's mesh system for a ship, or a ship and quay wall, uses ship length, width, draft, and coordinates for the center of gravity. Second, a wave force in the frequency domain is computed using regular 
waves, which have a unit wave height with wave frequency, direction, water depth, and mooring conditions. Next, the moment of momentum for a moored ship on an irregular wave field was obtained by the Bretschneider spectrum using significant wave height, period, and wave direction. Then, moored ship motion from short period waves was computed from the momentum. Finally, we estimated an allowable wave height for loading and unloading using the computed ship motion.

\section{- Computational method of ship oscillation quantity considering harbor resonance}

The flow chart for computing ship oscillation considering harbor resonance is shown in Figure 9. Inputs to the model are ship length, width, draft, and coordinates for the center of gravity. A wave force in the frequency domain was computed using a regular wave with unit wave height and a long wave period of over $30 \mathrm{~s}$. The moment of momentum for a moored ship on an irregular wave field was obtained from the Bretschneider spectrum using significant wave height, period, and wave direction. The moment of momentum for a moored ship using short wave periods of under $30 \mathrm{~s}$ was obtained from same procedure as for long waves. Then, the model combined the moments of momentum for a ship on both short period and long period waves, including resonant periods, in vectors. Moored ship motion, including resonant periods of the harbor, was obtained by computing moored ship motion using the combined moments of momentum.

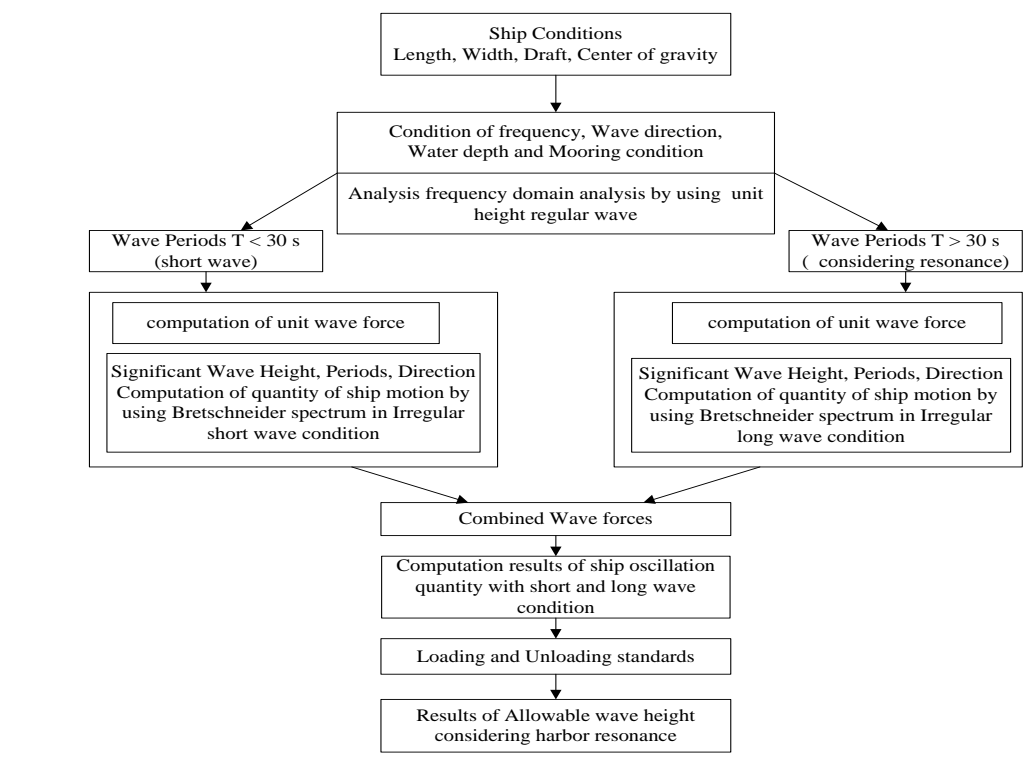

Figure 9. Flow chart of the computational procedure for ship oscillation quantity considering harbor resonance.

\section{Verification of the ship model}

\section{- Computational conditions for verification}

Ship conditions for verifying the model are listed Table 2; they are ship weight 45,500 DWT, length $180 \mathrm{~m}$, width $31 \mathrm{~m}$, draft $8.915 \mathrm{~m}$, and with 8 mooring lines, 12 fenders, and a water depth of $14 \mathrm{~m}$. In addition, wave conditions for verifying the model are listed in Table 3; they are three cases of short period waves, and all wave conditions include harbor resonance. In case 1 , the wave conditions include a significant wave height of $0.73 \mathrm{~m}$ and wave period $10.28 \mathrm{~s}$. In case 2, the significant wave height is $0.77 \mathrm{~m}$ and wave period is $11.66 \mathrm{~s}$. In case 3 , the significant wave height is $0.83 \mathrm{~m}$ and wave period is $11.57 \mathrm{~s}$. In all cases, the harbor resonance condition is a significant wave height of $0.15 \mathrm{~m}$ and wave period of $146 \mathrm{~s}$ and wave direction to the ship is $75^{\circ}$. 
The ship conditions for verifying the model were the same as that used by Kubo et al. (2001) in their field measurements of ship motion.

\begin{tabular}{|c|c|}
\hline $\begin{array}{c}\text { Table 2. Ship and mooring condition } \\
\text { for ship model verification. }\end{array}$ \\
\hline Weight & 45,500 tons \\
\hline Length & $180 \mathrm{~m}$ \\
\hline Width & $31 \mathrm{~m}$ \\
\hline Draft & $8.915 \mathrm{~m}$ \\
\hline Wetted area & $5876.04 \mathrm{~m}^{2}$ \\
\hline Mooring lines & $8 \mathrm{ea}$ \\
\hline Fender & $12 \mathrm{ea}$ \\
\hline Water depth & $14 \mathrm{~m}$ \\
\hline
\end{tabular}

\begin{tabular}{|c|c|c|c|}
\hline Short waves conditions & Case 1 & Case 2 & Case 3 \\
\hline $\mathrm{H}_{\mathrm{s}}(\mathrm{m})$ & 0.73 & 0.77 & 0.83 \\
\hline $\mathrm{T}_{\mathrm{s}}(\mathrm{s})$ & 10.28 & 11.66 & 11.57 \\
\hline Wave direction $\left(^{\circ}\right)$ & 75 & 75 & 75 \\
\hline \multicolumn{4}{|c|}{$\begin{array}{l}\text { Long waves condition } \\
\text { (harbor resonance condition) }\end{array}$} \\
\hline $\mathrm{H}_{\mathrm{s}}(\mathrm{m})$ & \multicolumn{3}{|c|}{0.15} \\
\hline $\mathrm{T}_{\mathrm{s}}(\mathrm{s})$ & \multicolumn{3}{|c|}{146} \\
\hline Wave direction $\left(^{\circ}\right)$ & \multicolumn{3}{|c|}{75} \\
\hline
\end{tabular}

\section{- Results of the ship model verification}

The numerical model for moored ship motion was verified by comparing it with field data for moored ship motion obtained by Kubo et al. (2001). The results of the numerical model, including harbor resonance, are shown in Figure 10, along with the field data and Kubo's model. Black shows the field data, gray indicates this model, and white indicates Kubo's model.

The results of this model show an error range of $10-15 \%$ to field data. The field data included wind and current, but the numerical model did not consider these effects. The results show that this model agrees with field data more than Kubo's model.

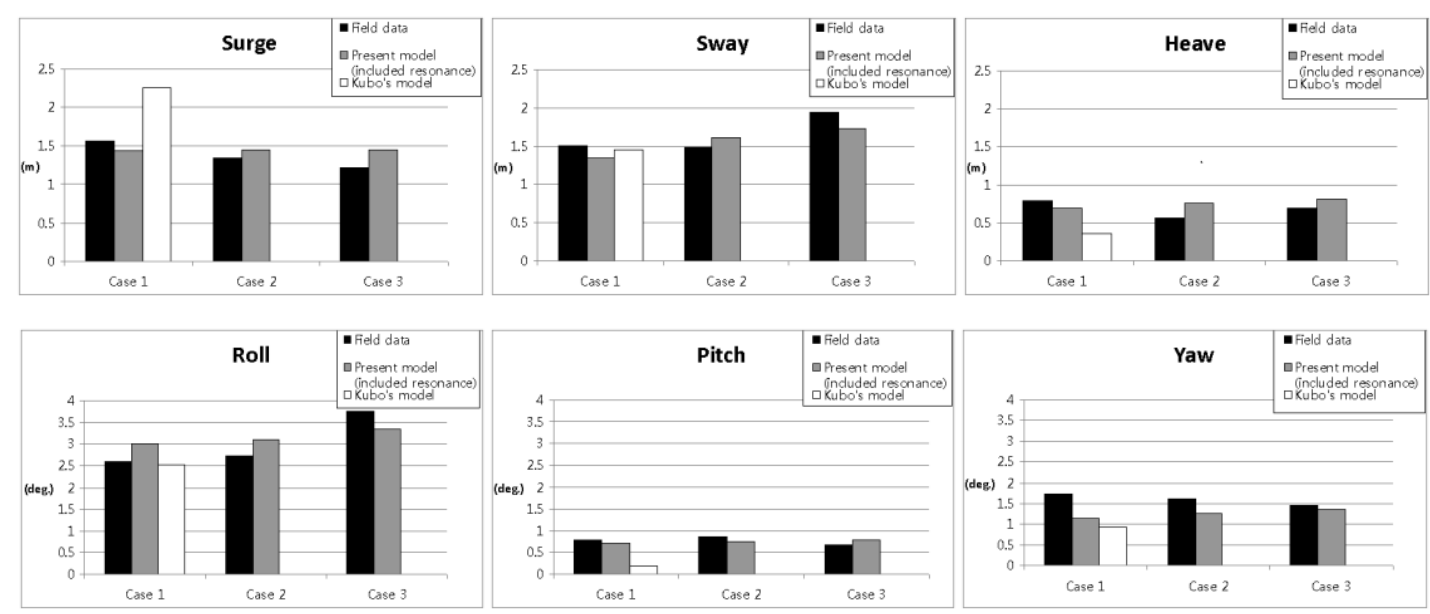

Figure 10. Comparison of results between computer simulation and field data with ship oscillation quantity.

\section{INVESTIGATION ON THE APPLICATION OF POHANG NEW HARBOR}

\section{Computational conditions for Pohang New Harbor}

In this study, validation of this method with an actual field harbor was carried out at Pohang New Harbor. The validation of this method was done by numerical simulation of short waves only, and with short waves as well as harbor resonance. The berth used for validation was on pier 8 , which is located near the east breakwater. 
The ship type used for validation was a general cargo ship, and the ship sizes were 5,000 DWT, 10,000 DWT, and 30,000 DWT. The mooring conditions were similar to those shown in Figure 11, with 12 mooring lines and 8 fenders. The initial tension of the mooring lines was set to $7 \%$ of their breaking load. The water depth at the berth was $10 \mathrm{~m}$. The dimensions for the three ship sizes are listed in Table 4.
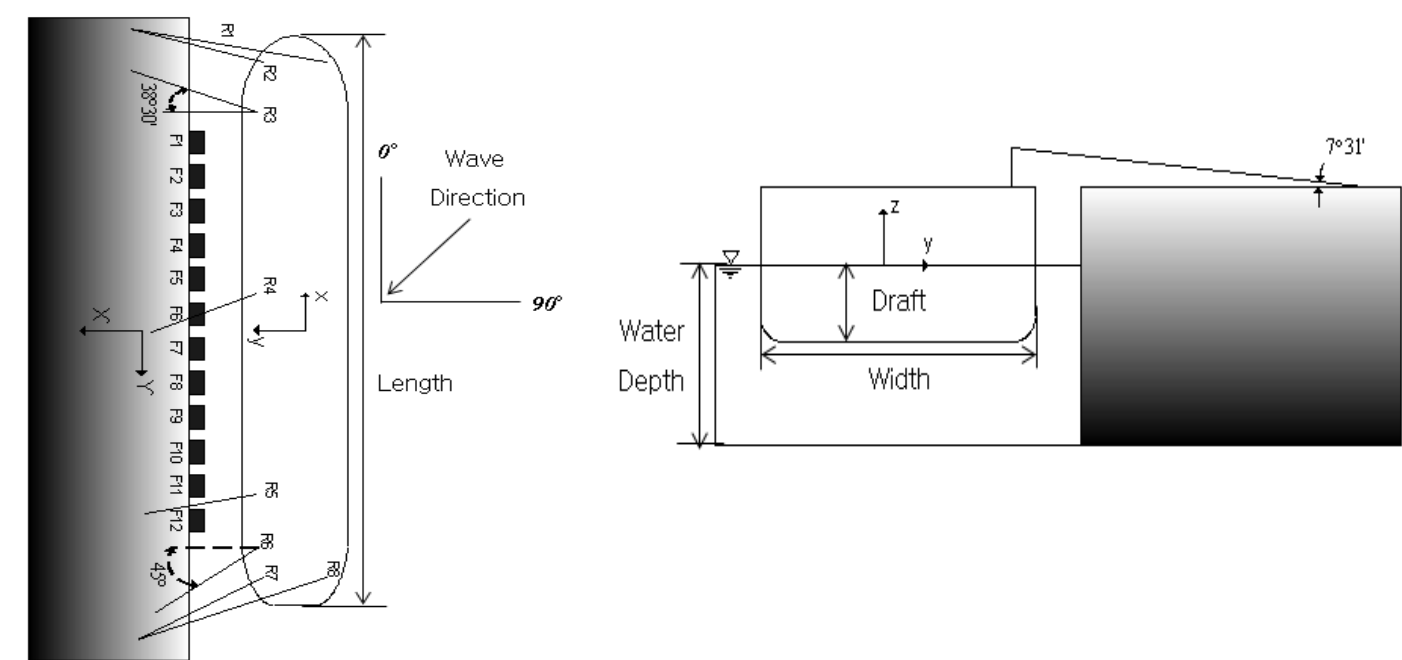

Figure 11. Definition sketches of the ship and mooring conditions.

\begin{tabular}{|c|c|c|c|}
\hline \multicolumn{4}{|c|}{$\begin{array}{l}\text { Table 4. Ship and mooring conditions for application of } \\
\text { Pohang New harbor }\end{array}$} \\
\hline & \multicolumn{3}{|c|}{ General cargo ship } \\
\hline Weight & 50,000 tons & 10,000 tons & 30,000 tons \\
\hline Length & $98 \mathrm{~m}$ & $120 \mathrm{~m}$ & $171.6 \mathrm{~m}$ \\
\hline Width & $14.0 \mathrm{~m}$ & $17.42 \mathrm{~m}$ & $26.0 \mathrm{~m}$ \\
\hline Draft & $4.5 \mathrm{~m}$ & $6.0 \mathrm{~m}$ & $7.0 \mathrm{~m}$ \\
\hline Wetted area & $2534.39 \mathrm{~m}^{2}$ & $3876.04 \mathrm{~m}^{2}$ & $4461.60 \mathrm{~m}^{2}$ \\
\hline Mooring lines & 8 ea & 8 ea & 8 ea \\
\hline Fender & 12 ea & 12 ea & 12 ea \\
\hline Water depth & $10.0 \mathrm{~m}$ & $10.0 \mathrm{~m}$ & $10.0 \mathrm{~m}$ \\
\hline
\end{tabular}

\begin{tabular}{|c|c|}
\hline \multicolumn{2}{|c|}{$\begin{array}{c}\text { Table 5. Short waves conditions of } \\
\text { Pohang New harbor }\end{array}$} \\
\hline \multicolumn{2}{|c|}{ Short waves conditions } \\
\hline $\mathrm{H}_{\mathrm{s}}(\mathrm{m})$ & $0.2,0.3,0.4,0.5,0.6,0.7,1.0$ \\
\hline $\mathrm{T}_{\mathrm{s}}(\mathrm{s})$ & $8,9,10,11,12$ \\
\hline Wave direction $\left(^{\circ}\right)$ & $15,45,75$ \\
\hline
\end{tabular}

\begin{tabular}{|c|c|}
\hline $\begin{array}{c}\text { Table 6. Long waves condition of } \\
\text { Pohang New harbor }\end{array}$ \\
\hline \multicolumn{2}{|c|}{$\begin{array}{c}\text { Long waves condition } \\
\text { (harbor resonance condition) }\end{array}$} \\
\hline $\mathrm{H}_{\mathrm{s}}(\mathrm{m})$ & 0.12 \\
\hline $\mathrm{T}_{\mathrm{s}}(\mathrm{s})$ & 60 \\
\hline Wave direction $\left(^{\circ}\right)$ & 15 \\
\hline
\end{tabular}

In addition, the wave conditions for model validation are listed in Tables 5 and 6 . The short wave conditions consisted of wave heights ranging from $0.2-1.0 \mathrm{~m}$, wave period ranging from $8-12 \mathrm{~s}$, and three different wave directions. The wave conditions including harbor resonance added $0.12 \mathrm{~m}$ to the wave height, and a wave period of $60 \mathrm{~s}$, which was obtained from field data. The wave direction to the moored ship was set at $15^{\circ}$, which was obtained from simulation results of the wave field. 


\section{Simulation results of ship oscillation quantity}

\section{- Simulation results for short waves only}

An example of the simulation results from short waves, not including harbor resonance, is shown in Figure 12. This figure represents the ship motion from changing wave height and periods when the ship size is 10,000 DWT and the wave direction is $75^{\circ}$. In the figure, the horizontal axis is wave height and the vertical axis is the ship motion.

With the same wave height, sway and roll motion tend to increase linearly as the wave period grows longer. Particularly, the roll motion increased significantly as wave period grew longer below wave periods of 8-10 s, but at wave periods 11-12 s roll motion changed only slightly as wave periods grew longer. We can say that roll motion is more sensitive to short period waves than long period waves. With the same wave period, sway and roll motion tends to increase linearly as wave heights grow. However, there is very little change in surge, heave, and yaw motion as wave heights grow. In addition, sway and roll motion increase as wave direction moves closer to being perpendicular to the ship's side.

\section{- Simulation results for short waves and harbor resonance together}

Simulation conditions when considering harbor resonance in addition to the short wave conditions included a wave at the resonant period. The ship and mooring conditions were similar to those under the short wave conditions alone. The simulation results while considering harbor resonance are shown in Figure 13. This figure represents the results for a ship size of 10,000 DWT and a wave direction of $75^{\circ}$ to the ship.

The simulation results when considering harbor resonance in addition to short waves show an increase in ship motion of 10-30\% over the results from short waves only. In particular, surge motion is obviously different from when the simulation includes only short waves. The results show that surge motion when considering harbor resonance tends to remain constant as the short wave periods and heights grow larger. From this, we can see that harbor resonance has a dominant effect on surge motion.

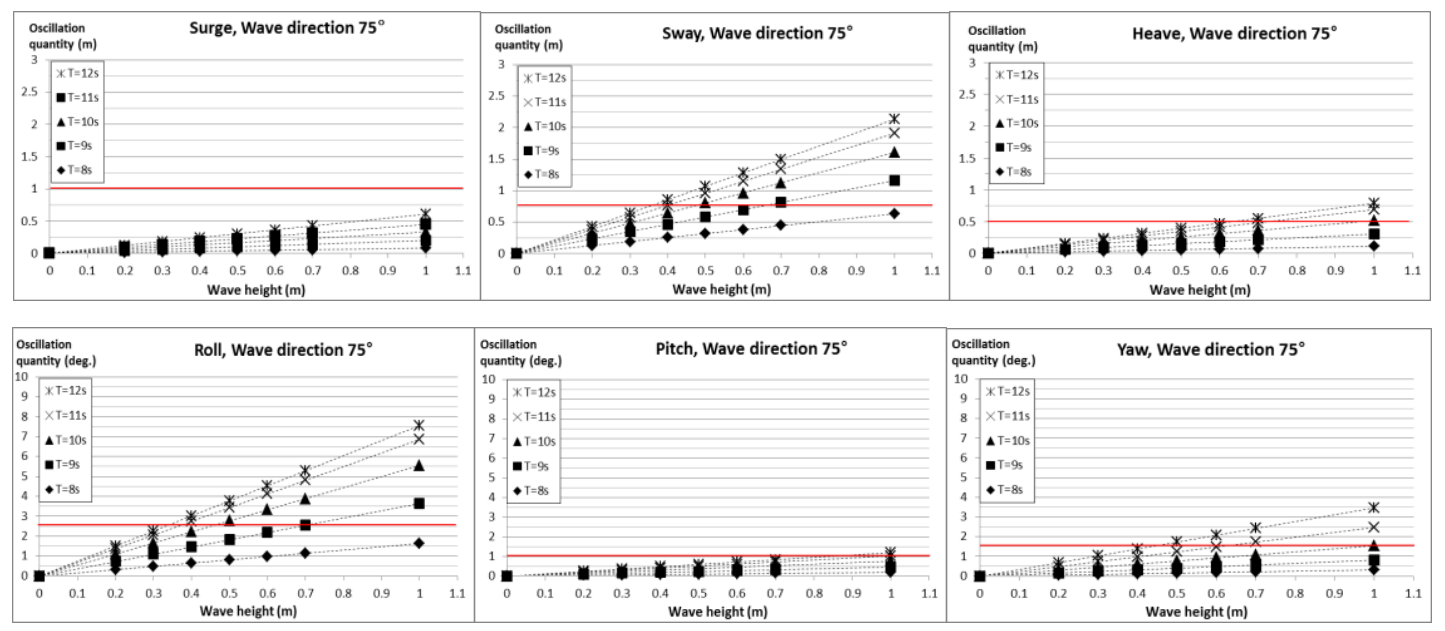

Figure 12. Computer simulation results of the ship oscillation quantity with short wave conditions (short wave only, 10,000 tons, wave direction $75^{\circ}$ ) 


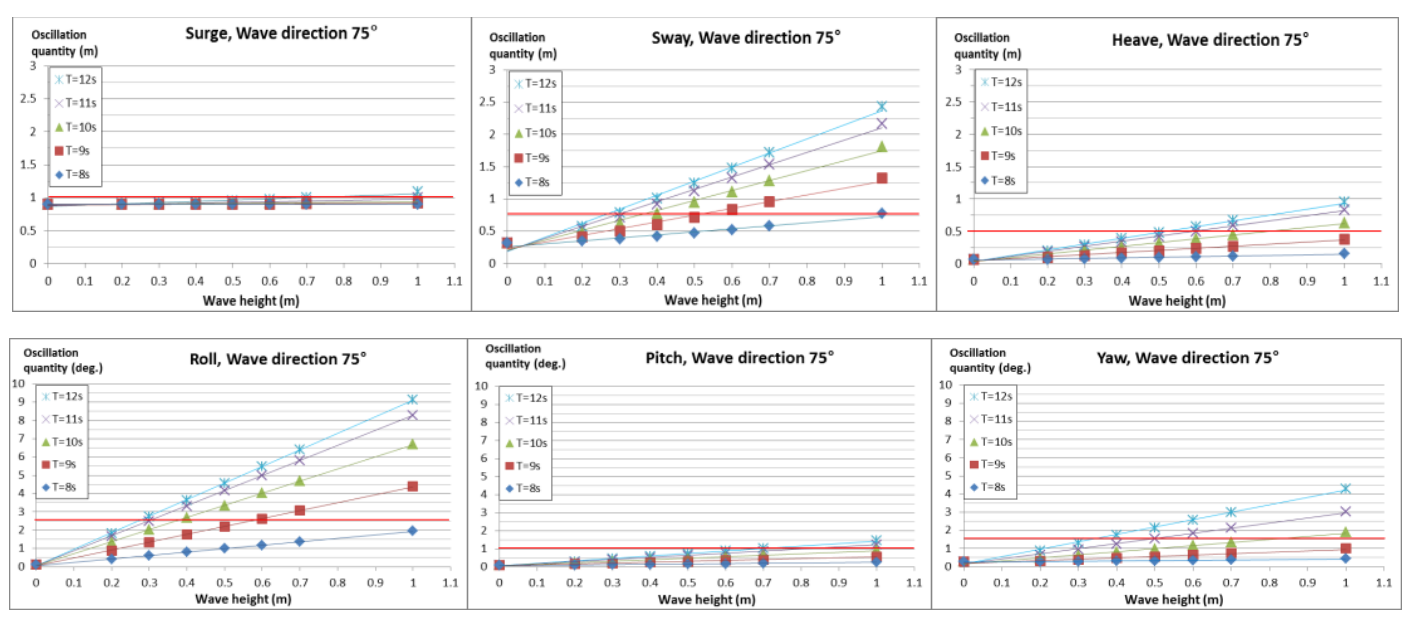

Figure 13. Computer simulation results of the ship oscillation quantity with short and long wave conditions (considering harbor resonance, 10,000 tons, wave direction $75^{\circ}$ )

\section{Comparison of results between short waves only and short waves with harbor resonance}

In this study, a comparison of the simulation results was done between short waves only and short waves with harbor resonance in order to show that harbor resonance has an effect on moored ship motion. The ship size used in the comparison was 10,000 DWT, and the short wave condition selected in this case was a wave height of $1.0 \mathrm{~m}$, wave period $1.2 \mathrm{~s}$, and wave direction of $75^{\circ}$. In addition, the harbor resonance condition added a wave height of $0.12 \mathrm{~m}$, wave period $60 \mathrm{~s}$, and wave direction of $15^{\circ}$.

The results of the comparison are shown in Figure 14. In this figure, black shows the results for short waves only for each ship size, and gray shows the results when also considering harbor resonance. Ship motion when considering harbor resonance is shown to be $10-30 \%$ greater than when the simulation includes only short waves. In particular, there is an obvious difference in surge motion. Surge motion when considering harbor resonance shows a noticeable increase as compared with the results from only short waves. It appears that the natural frequency of the surge motion matched the resonant frequency of the harbor. As ship size increases, the effect of harbor resonance on surge and heave motion tends to increase. However, as the ship size decreases, the effect of harbor resonance on roll, pitch, and yaw motion tends to increase.
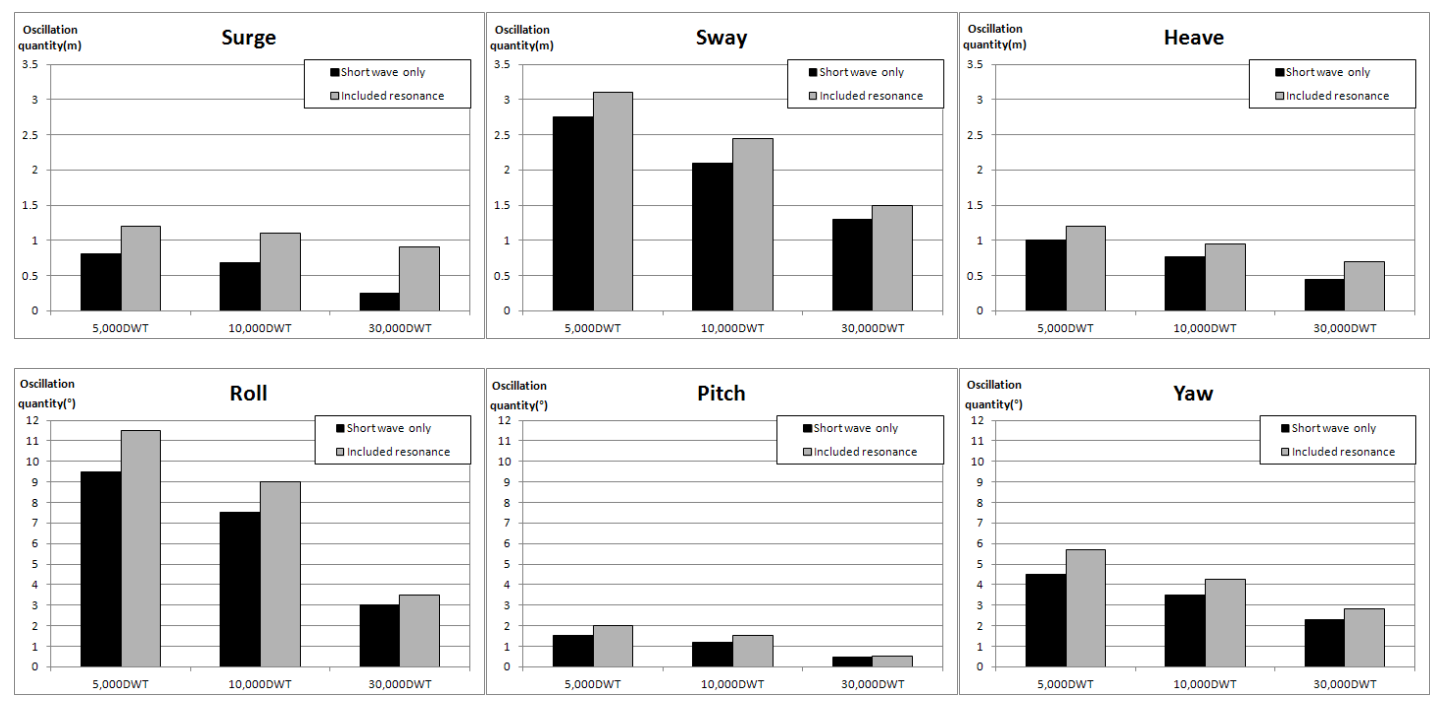

Figure 14. Comparison of results between short waves only and considering harbor resonance. 


\section{CONCLUSIONS}

This paper proposes a computational method for predicting moored ship motion considering harbor resonance, and estimates the effects of harbor resonance on moored ship motion. This method was verified with field measurements from actual moored ship motion (5,000-30,000 DWT-sized ships), and with wave and down time data records from an actual harbor (Pohang New Harbor). The following conclusions were drawn from this study:

- The proposed method for simulating moored ship motion considering harbor resonance was verified with field data from actual moored ship motion. The simulation of moored ship motion considering harbor resonance provides results that are more similar to field data than when harbor resonance is not considered.

- The simulation results of moored ship motion when harbor resonance was considered showed an increase in ship motion of $10-30 \%$ over the results when harbor resonance was not considered. In particular, surge motion shows an obvious increase.

- The effect of harbor resonance on surge and heave motion tends to increase as ship size increases.

However, the effect of harbor resonance on roll, pitch, and yaw motions tends to increase as ship size decreases.

- Moored ship motions increase when waves approach from the side of the ship. The increased ship motion was due to increased sway and roll.

This computational method for estimating moored ship motion considering harbor resonance is useful for harbor design when the harbor resonance occurs frequently due to infragravity waves and long waves. Harbor design using this method can improve harbor stability and increase the harbor working day.

\section{ACKNOWLEDGEMENTS}

This research was supported by Basic Research in Science and Engineering Program (2012-0007754) through the National Research Foundation (NRF) funded by the Ministry of Education, Science and Technology of Korea. This support is greatly appreciated.

\section{REFERENCES}

Dally, W. R., Dean, R. G., and Dalrymple, R. A. 1985. Wave Height Variation Across Beaches of Arbitrary Profile, J. of Geophysical Research, Vol 90, No. C6, 11917-11927.

Dalrymple, R. A., Kirby, J. T., and Hwang, P. A. 1984. Wave Diffraction due to areas of high energy dissipation, J. Waterway, Port, Coastal and Ocean Eng., 110, 67-79.

Demirbilek, Z., 1994. Comparison Between REFDIFS and CERC Shoal Laboratory Study, Unpublished Report, Waterways Exp. Station, Vicksburg, MS, 53.

Demirbilek, Z., Xu, B. and Panchang, V. 1996. Uncertainties in the Validation of Harbor Wave Models, Proceedings of 25th ICCE, 1256-1267.

Demirbilek, Z., and Panchang, V. 1998. CGWAVE : A Coastal Surface Water Wave Model of the Mild Slope Equation. Technical Report CHL-98-xx, U.S. Army Corps of Engineer, PP. 6-11.

Kirby, J. T. and R. A. Dalrymple, 1986. Modeling Waves in Surfzones and Around Islands, J. of Waterway, Port, Coastal and Ocean Engineering , ASCE, 112(1), 78-93. 
Madsen, O.S. 1976. Wave Climate of the Continental Margin: Elements of its Mathematical Description, Marine Sediment Transport and Environmental Management (eds. D. Stanley and D.J.P. Swift), John Wiley, New York, 65-87.

Molen, W., H. Ligteringen, J. C. vander Lem, J. C. M. de Waal, 2003, Behavior of a Moored LNG Ship in Swell Waves. J. of Waterway, Port, Coastal, and Ocean Engineering, ASCE, 129(1), 15-21.

Sakakibara, S., K. Saito and M. Kubo 2001. A study on Long-Period Ship Motions in a Harbor Induced by a Resonant Large Roll Motion Under Long-Period Waves, Proceedings of ISOPE, 326-333.

Ueda, S. and S. Shiraisi. 1988. The allowable ship motions for cargo handling at wharves. 27(4), Report of port and harbour research. Inst., Japan, 3-61.

Masayoshi Kubo, Shigeki Sakakibara, Katsuhiko Saito. 2001, A study on Long-Period Moored Ship Motions in a Harbor Induced by Resonant Large Roll Motion Under Long-Period Waves, Proceedings of ICCE, 326 333. 